\title{
COMPARISON OF 1.8 GHZ CELLULAR OUTDOOR MEASUREMENTS WITH AWAS ELECTROMAGNETIC CODE AND CONVENTIONAL MODELS OVER URBAN AND SUBURBAN REGIONS OF NORTHERN INDIA
}

M V S N Prasad*, Saurabh Gupta \& M M Gupta

National Physical Laboratory, Dr K S Krishnan Road, New Delhi-110012, India

*mvsnprasad@gmail.com

Abstract:

Propagation modeling is an important component of system design and helps to avoid surprises when the actual service begins in the case of wireless systems. Testing of various available models with the experimentally generated data helps to identify the suitable model which can be deployed for the design of future generation of mobile communication systems. This requires raising of new data sets which can be achieved by conducting experiments. With this objective the present study reports the narrowband signal level measurements of 11 GSM base stations in the urban, dense urban and suburban regions of Delhi in northern India. Comparison of the observed data has been carried out with electromagnetic models like AWAS and other empirical models like ITU-R, Cost 231 Hata, Walfisch-Ikegami and Dmitry. Based on the comparison mean prediction error and standard deviations have been deduced. High path loss exponents close to the base station were observed and AWAS electromagnetic code and ITU-R methods reported good agreement with the observed results compared with other methods.

Key words: electromagnetic code, prediction methods, $1.8 \mathrm{GHz}$ measurements, pathloss 


\section{Introduction}

Frequencies currently used by public safety organizations, other emergency services and cellular systems are typically below $2.4 \mathrm{GHz}$. Only the $3 \mathrm{G}$ services and wimax broad band services are being allocated between 2 to $3.5 \mathrm{GHz}$. The path loss information in these frequency bands is vital for the determination of coverage area of transmitter station/base station placement and optimizing it. Small scale parameters usually provide statistical information on local field variations [1]. An extensive survey of various propagation models for mobile communication is given by Sarkar et al. [2]. They described the models suitable for macrocell and microcell scenarios suitable for outdoor environment. To improve the performance of the existing services and to design new systems, modeling of the radio wave propagation effects is essential and it gives insight into the propagation mechanisms and phenomena affecting wireless communication. This can be achieved by generating new data sets and comparing the existing models with the observed data and modifying the models to suit the site specific conditions of given sites. On this aspect Medeisis and Kajackas [3] presented the comparison of Hata model with measurements in urban and rural zones at Lituania at 160, 450, 900 and $1800 \mathrm{MHz}$ band and presented modified coefficients over the above region. Prasad et al. [4] based on extensive data sets raised over northern, western, eastern and southern regions of India in the VHF and UHF bands, carried out model tuning of well known Hata model over these regions and presented new sets of offset factor and slope parameter. Stern et al [5] described the development of an adaptive RF propagation prediction program for land mobile radio systems. The program is based on transmitter power, frequency, base and mobile antenna heights, data files of signal strength measurements. Anthony Lion et al., [6] claimed that theirs is the first study to compare the path gain and signal fading on fixed non los links in suburban macrocell 
environments over the frequencies $220 \mathrm{MHz}, 850 \mathrm{MHz}$ and $2 \mathrm{GHz}$. They reported that signal fade depth drops off rapidly as frequency decreases. It varies with distance, time and averaged wind speed. A link that experiences severe fading at $1.9 \mathrm{GHz}$ is relatively unaffected at $220 \mathrm{MHz}$ Sarkar et al. [7] have shown that placing the antenna on top of a tower as in the case of mobile communications produces undesirable effects. The signal strength goes through a series of maxima and minima. If the antenna is located $100 \mathrm{~m}$ or higher the lobing effects get reduced due to the weakening of the image component due to losses in the ground. Using the electromagnetic simulation tool AWAS [8] based on Sommerfeld formulation they have shown that computed fields were very close to the experimentally observed results of Okumara [9]. It was observed that tool produces interesting results in the near field region than in the far field region. In another paper Sarkar et al. [10] advocated the concept of placing the transmitting antenna closer to the ground which requires less transmitter input power to achieve higher capacity. They have shown that capacity can be increased by tilting it slightly upward in order to minimize the interference between the fields produced by the antenna and its image.

With the this back ground in the present study an attempt is made to investigate the suitability of various prediction models using the $1.8 \mathrm{GHz}$ cellular frequency narrowband measurements conducted in urban and suburban areas of Delhi in northern India. In total 11 base stations were utilized in the study out of which 3 stations fall in the urban category, 6 in dense urban category and 2 in suburban category. The observed signal levels converted into path loss values were compared with different empirical models. Apart from this the major contribution of this study is the comparison of the above results with the predicted ones of AWAS electromagnetic code in the near field and far field zones. The deviations of all the methods and standard deviations are 
presented. Pathloss exponents and break point distances have been deduced. Some preliminary results pertaining to dense urban regions of these measurements were presented in [11].

\section{Experimental details}

The carrier signals of various GSM base station transmitters located in the dense urban/urban environments of New Delhi area operating in the $1.8 \mathrm{GHz}$ belonging to Idea cellular network have been monitored with Nokia GSM receiver (model 6150) generally used as a drive-in tool for planning cellular network along with GPS receiver to know the latitude and longitude of the mobile. The sensitivity of receiver is $-102 \mathrm{dBm}$. The transmitting powers of all the station are $+43 \mathrm{dBm}$. Out of the 11 stations 3 are located in urban, 6 in dense urban and remaining 2 are in suburban environment. The details of the base stations are shown in Table 1. The estimated measurement r.m.s. error is around $1.5 \mathrm{~dB}$.

Table 1. Experimental details of base stations

\begin{tabular}{|l|l|l|l|l|l|l|}
\hline $\begin{array}{l}\text { Name of base } \\
\text { station }\end{array}$ & Environ & $\begin{array}{l}\text { Gain Tx } \\
\text { ant.(dBi) }\end{array}$ & $\begin{array}{l}\text { Beamwidth } \\
\text { (Horiz) deg }\end{array}$ & $\begin{array}{l}\text { Beamwidth } \\
\text { (Vert) deg }\end{array}$ & $\begin{array}{l}\text { Heigh } \\
\text { tof tx } \\
\text { Ant. } \\
\text { (m) }\end{array}$ & $\begin{array}{l}\text { Near } \\
\text { field } \\
\text { distance(m } \\
\text { (.MP } \\
\text { House(MPH) }\end{array}$ \\
\hline $\begin{array}{l}\text { 2.Malcha } \\
\text { Marg(MAM) }\end{array}$ & Urban & 18.0 & 65 & 7 & 24 & 867 \\
\hline 3.Rohini(RHN) & Urban & 18.0 & 65 & 7 & 24 & 867 \\
\hline $\begin{array}{l}\text { 4.Arunachal } \\
\text { (ACL) }\end{array}$ & $\begin{array}{l}\text { Dense } \\
\text { urban }\end{array}$ & 17.5 & 65 & 7 & 32 & 1157 \\
\hline $\begin{array}{l}\text { 5. Inner } \\
\text { circle(IC) }\end{array}$ & $\begin{array}{l}\text { Dense } \\
\text { urban }\end{array}$ & 18.0 & 65 & 7 & 22 & 795 \\
\hline $\begin{array}{l}\text { 6.Omkarnagar } \\
\text { sec-1(OM-1) }\end{array}$ & $\begin{array}{l}\text { Dense } \\
\text { urban }\end{array}$ & 18.0 & 65 & 7 & 24 & 867 \\
\hline $\begin{array}{l}\text { 7.Omkarnagar } \\
\text { sec-2(OM-2) }\end{array}$ & $\begin{array}{l}\text { Dense } \\
\text { urban }\end{array}$ & 18.0 & 65 & 7 & 24 & 867 \\
\hline
\end{tabular}




\begin{tabular}{|l|l|l|l|l|l|l|}
\hline 8.Trinagar(TRN) & $\begin{array}{l}\text { Dense } \\
\text { urban }\end{array}$ & 18.0 & 65 & 7 & 24 & 867 \\
\hline $\begin{array}{l}\text { 9.I.P.Extension } \\
\text { (IPE) }\end{array}$ & $\begin{array}{l}\text { Dense } \\
\text { urban }\end{array}$ & 17.5 & 65 & 7 & 27 & 976 \\
\hline $\begin{array}{l}\text { 10.Brij vihar } \\
\text { (BJV) }\end{array}$ & Sub- urban & 18.0 & 65 & 7 & 24 & 976 \\
\hline $\begin{array}{l}\text { 11. Vasundhara } \\
\text { (VDR) }\end{array}$ & Sub- urban & 18.0 & 65 & 7 & 24 & 976 \\
\hline
\end{tabular}

Height of the mobile antenna $=1.5 \mathrm{~m}$

\section{Prediction methods}

The following prediction methods have been utilized in this study. 1. AWAS numerical code based on electromagnetic modeling [8] 2. ITU-R method [12] 3. Dmitry model [13] 4. COST 231 Walfisch-Ikegami method [14] 5. COST 231 Hata method [15]

3.1AWAS numerical electromagnetic code: AWAS electromagnetic code has been utilized to compare the predictions in the near field and far field zones. It is utilized to compute the path loss values with a dielectric constant of 4 and conductivity of $2 \times 10^{-4}$ over real ground. The commercially available computer program is capable of analyzing wire antennas operating in transmitting and receiving modes as well as analyzing wire scatterers. The technique is based on the two-potential equation for the distribution of wire currents. This integro-differential equation is solved numerically using the method of moments with a polynomial approximation for the current distribution. The influence of ground is taken into account using Sommerfeld's approach with numerical integration algorithms developed exclusively for this program. The program evaluates the fields in the near field and far field region and these were converted into path losses to compare with the observed values.

3.2 Dmitry model: Dmitry method comes under stochastic category In the case of Dmitry method propagation modeling is done by explicitly considering random diffuse scattering at 
street level in the vicinity of the mobile and propagation over clutter as a deterministic problem. Authors compare their model over an urban environment with COST 231 Hata, Walfisch-Bertoni models at $2 \mathrm{GHz}$, for base station antenna height of $25 \mathrm{~m}$, clutter height of $20 \mathrm{~m}$ and street width of $30 \mathrm{~m}$ and mobile antenna height of $2 \mathrm{~m}$. In another study Yarkoni \& Blaunstein et al. [16] investigated the total received signal for mobile antenna in urban region based on multi parametric stochastic approach. Authors claim that their equations can predict different propagation situations and path loss in various urban channels for different heights of base station and mobile terminal antennas.

3.3 ITU-R model: ITU-R recommendation 1411-4 provides prediction capability for outdoor short range radio communication systems and radio local area networks in the frequency range $300 \mathrm{MHz}-100 \mathrm{GHz}$ and gives closed-form algorithms both for site-specific and site-general calculations. The model is applicable to urban high rise, low rise urban, suburban, residential and rural areas. In the case of dense urban or urban under non los category the range of applicability of this model is base station antenna height $\left(\mathrm{h}_{\mathrm{b}}\right)$ from 4 to $50 \mathrm{~m}$, mobile antenna height $\left(\mathrm{h}_{\mathrm{m}}\right)$ from 1 to $3 \mathrm{~m}$, frequency (f) from 800 to $5000 \mathrm{MHz}$, and 2 to $16 \mathrm{GHz}$ for $\mathrm{h}_{\mathrm{b}}<\mathrm{h}_{\mathrm{m}}$ and distance (d) from 20 to $5000 \mathrm{~m}$. In the case of suburban regions any height of $\mathrm{h}_{\mathrm{m}}$ can be used, $\Delta \mathrm{h}_{\mathrm{b}}$ from 1 to 100 $\mathrm{m}\left(\Delta \mathrm{h}_{\mathrm{b}}=\mathrm{h}_{\mathrm{b}} \cdot \mathrm{hr}\right.$, $\mathrm{hr}$ is average roof height of buildings $), \Delta \mathrm{h}_{\mathrm{m}}$ from 4 to $10 \mathrm{~m}\left(\Delta \mathrm{h}_{\mathrm{m}}=\mathrm{hr}-\mathrm{h}_{\mathrm{m}}\right)$, street width (w) ranging from 10 to $25 \mathrm{~m}, \mathrm{~d}$ from 10 to $5000 \mathrm{~m}$. Multiscreen diffraction terms are incorporated to account the roof top diffractions in the urban zone. Here the average roof top height is used. In the nonline-of-sight(nlos) category for roof tops of similar height the loss is expressed as sum of free space loss, multiscreen diffraction loss and loss due to coupling of wave propagation along the multiscreen path into the street where mobile is located. Here width of the street is taken into consideration. For more details the reader can refer to ITU-R 
recommendation. In the case of suburban zones propagation model based on geometrical optics is given.

3.4 Walfisch-Ikegami method (WI method): This is one of the most widely used analytical model to predict the path loss which consists of a combination of Walfisch and Ikegami models. Here the path loss is combination of free space loss, multiple knife-edge diffraction to the top of the final building and single diffraction and scattering process down to street level. The model is applicable to frequencies between 800 to $2000 \mathrm{MHz}$; hb between 4 and $50 \mathrm{~m}, \mathrm{~h}_{\mathrm{m}}$ between 1 and $3 \mathrm{~m}$ and distances between 200 to $5000 \mathrm{~m}$.Performance of the model is poor when $\mathrm{h}_{\mathrm{b}}$ is less than $\mathrm{h}_{\mathrm{r}}$. In the present study this model is utilized for street width of $20 \mathrm{~m}$ and roof heights of 12 and $15 \mathrm{~m}$.

3.5 COST 231 Hata Method: The Okumara-Hata model for medium to small cities has been extended to the frequency between 1500 and $2000 \mathrm{MHz}$ The last term becomes zero for medium sized cities and suburban areas and is $3 \mathrm{~dB}$ for metropolitan areas. The model is applicable to distances between 1 and $20 \mathrm{~km}, \mathrm{~h}_{\mathrm{b}} 30$ to $200 \mathrm{~m}$ and $\mathrm{h}_{\mathrm{m}} 1$ to $20 \mathrm{~m}$.

\section{Results}

The comparison of the above discussed models with the observed results for all the eleven base stations is carried out and presented in figures 1 to 11 . Figures 1 to 3 depict the comparison for MPH, MAM and RHN base stations in the urban region. Similarly figures 4 to 9 represent the same for ACL, IC, OM-1, OM-2, TRN and IPE base stations falling in the dense urban region. Figures 10 and 11 represent the suburban region for base stations BJV and VDR base stations. AWAS computed losses are shown in the near field and far field regions. Variation of path loss is more significant at distances close to the transmitter i.e.in the near field region. Hence comparison of results in the near field region is more important. The near field distances 
computed based on antenna height, wavelength are also shown in table 1. Only in the case of VDR base station data in the near field region is not available.

4.1 Urban region: Comparison of the model predicted values with the observed values for the urban region are given in figures 1-3. In all these three figures at distances very close to the transmitter high path loss values with large variance ranging from 100 to $160 \mathrm{~dB}$ were observed, at distances around $500 \mathrm{~m}$ or so path losses decrease and stabilize around $150 \mathrm{~dB}$ and remain around this value for the remaining distances. In all the three figures AWAS computed path losses follow the trend of observed values with good agreement in the near field and far field zones. In the near field zone the variability of observed path loss is high compared with far field zone. In figure 2 AWAS computed losses follow the observed values very nicely till the maximum distance of $2000 \mathrm{~m}$. But in all the three figures AWAS computed curves pass through the exact centre of cluster of path loss values. In figure 3 AWAS computed values at $50 \mathrm{~m}$ distance coincides with observed values. ITU-R model follows the observed values like AWAS curve upto distances of $200 \mathrm{~m}$ and then deviates little sharply. WI and COST 231 Hata curves follow the lower cluster of path loss values in the near field zones and coincide with AWAS curves from $2000 \mathrm{~m}$ in all the figures. Dmitry's model underestimates the observed data by large values in all the three figures.

4.2 Dense Urban zone: Figures 4 to 9 represent the comparison in the dense urban region. Here also as in the urban region AWAS and ITU-R computed curves pass through the cluster of path loss values at all distances in figures 4 and 5 and deviate beyond $1500 \mathrm{~m}$ in figures 6 to 8 . WI and COST 231 Hata computed curves follow the lower distance part of observed path loss clusters in all the figures. Dmitry model underestimates the observed values by 20 to $30 \mathrm{~dB}$ in all the figures. In figures 4 and 5 both the AWAS and ITU-R curves follow the observed values 
throughout the range of distances. It could be due to the fact this observed path loss values after a certain distance does not decrease further and remains more or less parallel to distance axis. This might have been caused by the signal undergoing wave guiding phenomena and radio waves getting reflected and diffracted between the buildings. Similarly wave guiding exhibited in urban region is seen in figure 2. In figure 9 observed data is available only from $600 \mathrm{~m}$ onwards to 1800 m. Here COST 231 Hata and WI curves follow the observed values. Dmitry's curve follows through the lower half of the observed path loss values.

4.3 Suburban region: In figure 10 at distances close to the transmitter and upto $1000 \mathrm{~m}$ or so path loss varies from 100 to $150 \mathrm{~dB}$ and at distances beyond $1500 \mathrm{~m}$ gets confined between 130 and $150 \mathrm{~dB}$. Here in suburban region AWAS curve passes through the centre of the cluster of observed path loss values. Both Hata and WI curves follow the AWAS curve from $2000 \mathrm{~m}$ onwards and give good agreement till 2000m. Here ITU-R curve and Dmitry's model underestimate the observed values. In ITU-R model prediction approach of the model varies from urban to suburban region. This could be the reason why in urban and dense urban regions it gives better agreement and deviates appreciably in suburban zones. In figure 11 data is available from $4000 \mathrm{~m}$ and the trend is similar to other base stations.

\section{Standard deviations of the prediction methods}

Based on the above comparison prediction errors of the models from the observed values have been deduced where prediction error is given by the difference of observed and predicted values. Standard deviations of all the base stations for the above methods have been deduced and are shown in the table 2 below.

Table 2. Standard deviations and mean errors (in $\mathrm{dB}$ ) of the prediction methods

\begin{tabular}{|l|l|l|l|l|l|}
\hline Base station & AWAS & ITU-R & WI & $\begin{array}{l}\text { COST 231 Hata } \\
\text { ME SD Smitry }\end{array}$ & SW \\
\hline
\end{tabular}




\begin{tabular}{|l|l|l|l|l|l|l|l|l|l|l|}
\hline & \multicolumn{2}{|l|}{ ME SD } & \multicolumn{2}{l|}{ ME SD } & \multicolumn{2}{l|}{ ME SD } & & \multicolumn{2}{l|}{ ME SD } \\
\hline 1.MPH & 5.74 & 9.41 & 1.46 & 12.10 & 5.89 & 26.20 & 6.94 & 25.04 & 38.86 & 43.90 \\
\hline 2.MAM & -2.25 & 5.67 & 0.93 & 8.23 & 13.13 & 15.13 & 14.82 & 14.18 & 26.23 & 3.96 \\
\hline 3.RHN & 0.76 & 22.88 & -3.91 & 7.79 & 10.70 & 21.41 & 10.98 & 20.30 & 9.89 & 5.68 \\
\hline 4.ACL & 21.64 & 15.30 & -0.30 & 11.55 & 2.03 & 10.79 & 12.13 & 10.01 & 16.40 & 26.08 \\
\hline 5.IC & 11.94 & 1.86 & 1.57 & 6.53 & 27.83 & 23.96 & 29.96 & 24.09 & 23.82 & 18.10 \\
\hline 6.ON-1 & 5.71 & 19.22 & -5.40 & 8.10 & 6.71 & 23.76 & 7.35 & 22.66 & 19.39 & 7.80 \\
\hline 7.ON-2 & 22.76 & 16.09 & -5.68 & 8.05 & 6.99 & 18.78 & 7.63 & 17.60 & 19.39 & 8.20 \\
\hline 8.TRN & 7.12 & 28.54 & -2.70 & 13.00 & 6.49 & 24.58 & 7.09 & 23.46 & 28.39 & 38.91 \\
\hline 9.IPE & -3.84 & 17.32 & -13.12 & 8.65 & -5.93 & 15.26 & -6.33 & 14.95 & 7.29 & 3.50 \\
\hline 10.BJV & 7.99 & 19.18 & 3.22 & 6.30 & -5.50 & 7.30 & -2.50 & 7.25 & 7.87 & 2.8 \\
\hline 11.VDR & -22.31 & 3.32 & -6.70 & 6.57 & -26.85 & 11.23 & -30.31 & 11.15 & -30.60 & 1.02 \\
\hline
\end{tabular}

In the above table 2, prediction error is calculated as the difference between observed and predicted loss for each method. While deducing standard deviations and mean prediction errors for each base station data points starting from $200 \mathrm{~m}$ onwards were utilized for all the methods. No prediction method gives agreement at distances before $200 \mathrm{~m}$ roughly corresponding to break point distances (these are explained in detail in section 7). In the urban/dense urban region AWAS numerical code predicted a lowest standard deviation of 1.86 for IC base station and lowest mean error for RHN base station (0.76). For MAM base station the mean error of -2.25 and standard deviation of 5.67 are reasonably good. Highest values of deviation 28.54 are seen for TRN base station. ITU-R method also predicts lowest deviation of 6.53 for IC base station and highest value of around 13 for TRN base station. The range of deviations for all urban/dense urban base stations in the case of WI method are seen between 10 to 26 , in the case of COST 231 Hata between 10 to 25, and in the case of Dmitry model are between 4 to 43 showing wide range of deviations.

For all the base stations in the urban/dense urban base stations taken together the average standard deviation for AWAS method is 13.36 and average error is 0.95 . The corresponding values for other methods are, for ITU-R 10.38 and -5.83 , for WI they are 20.73 and 0.02 , for 
COST 231 Hata around 19.99 and 0.305, and finally for Dmitry they are 23.7 and 23.05.

Compared with other methods AWAS and ITU-R methods depicted lower values of deviation and mean prediction error when all stations taken together and also when stations are examined individually. In the case of two suburban base stations AWAS gives average deviation of 11.25 and average error of -7.16 . The corresponding values for ITU-R are 6.43 and -1.74 , for WI they are 9.26 and 16.17, for COST 231 Hata are 9.2 and -16.4 and Dmitry they are around 1.91 and 11.36. In this case lowest deviation is seen from Dmitry model.

\section{Pathloss exponents}

The observed values of path loss for all the base stations have been deduced for distances ranging from $50 \mathrm{~m}$ to $3.5 \mathrm{~km}$. Path loss exponents from the data have been computed from the equation 1 shown below using the observed path losses for various distances

$$
\mathrm{L}=\mathrm{L}_{0}+10 \mathrm{n} \log \mathrm{d}+\mathrm{S}
$$

Where $\mathrm{L}$ is the path loss deduced for various distances, $\mathrm{L}_{0}$ is the path loss at one meter and $\mathrm{d}$ is

the distance in meters, $\mathrm{S}$ is the shadow fading in $\mathrm{dB}$. Using the approach given in reference

[17] of Erceg et al., the path loss exponent $\mathrm{n}$ has been deduced. In the above equation

$$
\mathrm{L}_{0}=20 \log \left(4 \prod \mathrm{d}_{0} / \lambda\right)
$$

where $\lambda$ is the wavelength corresponding to $1800 \mathrm{MHz}$ and $\mathrm{d}_{0}$ is taken as one meter. $\mathrm{s}$ is the shadow fading variation and varies from location to another within given macrocell. It tends to be Gaussian in a given macro cell denoting shadow fading as lognormal. It can be expressed as s $=\mathrm{y} \sigma$, where $\mathrm{y}$ is a zero mean Gaussian variable of unit standard deviation and $\sigma$ the standard deviation of $s$ is itself a Gaussian variable over macrocells. L is taken from the observed path 
loss values. Using the above values the path loss exponent ' $n$ ' has been deduced. In general at distances close to the transmitter exponents of the order of 7 are observed and then they fall steeply up to a value of 4 around $400 \mathrm{~m}$ and remains steady for the remaining distances. A typical figure of the above exponent variation for OM-1 base station is shown in figure 12. At distances close to the transmitter exponents of 6 to 7 were observed and start falling steeply upto $300 \mathrm{~m}$ and stabilize around 3.5 . Figures 13 and 14 depict the variation of path loss exponents for MAM base station representing urban region and BJV base station representing suburban region. In figure 13 exponents start falling between 6 to 7 and at a distance of $200 \mathrm{~m}$ stabilizes around 3.5. In figure 14 same trend is exhibited and at around $300 \mathrm{~m}$ or so the exponents stabilize to a value of 3 .

\section{Break point distances}

The break point has been deduced as the distance at which the slope of the curve (the path loss exponent vs distance) changes. In Figure 1 it changes at $200 \mathrm{~m}$. In the case of other base stations same approach has been followed and the values are shown in table 3

Table 3. Break point distances observed from data.

\begin{tabular}{|l|l|l|}
\hline Base station & Height of tx. ant $(\mathrm{m})$ & Observed break point $(\mathrm{m})$ \\
\hline 1.MPH & 24 & 500 \\
\hline 2.MAM & 22 & 200 \\
\hline 3.RHN & 24 & 200 \\
\hline 4.ACL & 32 & 400 \\
\hline 5.IC & 22 & 200 \\
\hline 6.ON-1 & 24 & 300 \\
\hline 7.ON-2 & 24 & 300 \\
\hline 8.TRN & 24 & 500 \\
\hline 9.IPE & 27 & - \\
\hline 10.BJV & 24 & 300 \\
\hline 11.VDR & 24 & - \\
\hline
\end{tabular}




\section{Discussion}

In the case of Erceg et al also [17] who made extensive measurements at $1.9 \mathrm{GHz}$ at New Jersey, Seattle and Chicago high path losses close to the transmitter were observed and then the loss was decreasing linearly with distance. In the present study the path loss is falling steeply up to 0.5 $\mathrm{km}$. The nature of variation of path loss exponent in the present study resembled to that of variation in Erceg et al's study. Steep transitions of path loss occur when the base station antenna height is close to the height of surrounding building roof tops. Hence the height accuracy of the base station antenna is especially significant if large prediction errors are to be avoided [18].Milanovic et al [19] have observed that in dense urban regions measurements show a very interesting feature. Path loss after the break point does not increase with distance. This could be probably due to the wave guiding effect of city streets as well as the existence of radio wave components reflected and diffracted on buildings reaching the receiver antenna. The path loss exponent in the present study showed this kind of trend. Herring et al., [20] observed large variance between received power as a function of distance. This showed that using a single value of path loss exponent for a particular neighbourhood as assumed in popular empirical models can lead to large errors in path loss estimates. For links of lengths of $1 \mathrm{~km}$ the number and types of objects between transmitter and receiver can vary significantly as a function of direction thus leading to this result. Similar large variance was also observed in the present study showing path loss exponents vary even in a given macrocell.

The major feature emerging from all the base stations is the high path loss values close to the base station and fall steeply up to distances between 200-500 m more or less corresponding to break point and then showing moderate variations beyond the break point. Clearly two slopes are 
seen one up to break point and second beyond break point. This can be explained that till the break point the dominant propagation mechanism is horizontal mode and then beyond this propagation mechanism changes to vertical one. This also has been observed by Barbiroli [21]. They observed that both the mechanisms are present at all distances and the distance at which the dominant mode changes from horizontal to vertical depends on the base station antenna height. Hence the height accuracy of the base station antenna is especially significant if large prediction errors are to be avoided. High path losses close to the transmitter require higher margins from operators. The deviation of all the prediction methods at closer distances to the transmitter is high due to the large path loss variation.

\section{Conclusions}

In the macro cellular urban, dense urban and suburban regions of Delhi, using the $1.8 \mathrm{GHz} \mathrm{GSM}$ band, narrowband signal level measurements were carried out for 11 base stations. The observed results were compared with AWAS electromagnetic code, ITU-R method, Walfisch-Ikegami method, COST 231 Hata method and Dmitry method. An analysis of prediction errors and standard deviations showed that AWAS electromagnetic code and ITU-R methods reported good agreement and lower standard deviations compared with other methods. The advantage of using AWAS electromagnetic code is that it does not require any building information and was able to compete with other empirical methods and followed the trend of observed data in most of the cases. High path losses and large path loss variance observed at closer distances to the transmitter were not explained by the prediction methods. It seems till the break point the dominant propagation mechanism is in horizontal mode and beyond this it changes into vertical one. The usefulness of this study is the comparison of AWAS predicted values in the near and far field regions of base stations. Path loss exponents and break point distances have been deduced 
and presented. High path loss exponents observed can make the operators to rethink on the

margins provided by them and this study is useful for the design of upcoming $3 \mathrm{G}$ and wimax

systems in these regions and similar regions.

\section{References}

1. M.F. Iskander and Z. Yun, "Propagation models for wireless communication systems", IEEE

Transactions o microwave theory and techniques, Vol50, No.3, pp 662-672, Mar2002

2. T. K. Sarkar, Z. Ji, K. Kim, A. Medouri and M. Salazar-Palma "A survey

of various propagation models for mobile communication", IEEE Antennas and propagation

magazine, 45, 3, 2003, pp 51-81

3. A. Medeisis and A. Kajackas "On the use of universal Okumura-hata propagation

prediction model in rural areas", Proceedings of the IEEE $51^{\text {st }}$ Vehicular Technology Conference, 3, 2000, pp. 1815- 1818

4. M.V.S.N.Prasad, K. Ratnamala, M.Chaitanya and P K.Dalela, "Terrestrial communication experiments over various regions of Indian subcontinent and tuning of Hata's model

Annals of telecommunications, Vol.63, no.3-4, pp 223-235, Mar-April, 2008

5. H.P. Stern, J.G. Hermes and S.Darbha, "An adaptive propagation prediction program for land mobile radio systems", IEEE Trans. Broadcasting, Vol.43, No.1, Mar1997, pp 56-62

6. A. Liou, K.N. Sivertsen, P.Arjmandi, G.Viswanathan, B. Diallo, S.Lancashire and D.G.

Michelson, "Characterization of fading on fixed wireless channels between $200 \mathrm{MHz}$ and $2 \mathrm{GHz}$ in suburban macrocell environments", IEEE Trans. Wireless communications, Vol.8, No.10, Oct 2009, pp 5356-5365

7. T. K. Sarkar, S. Burintramart, N. Yilmazer, S. Hwang, Y. Zhang, A. De and M. Salazar-Palma,

"A discussion about some of the principles/practices of wireless communication under a

Maxwellian framework", IEEE Transactions on antennas and propagation, Vol. 54, Issue 12, Dec. 2006, pp 3727-3745.

8. A. R. Djordjevic, M. B. Bazdar, T. K. Sarkar and R. F. Harrington, “AWAS for windows version 2.0: Analysis of wire antennas and scatterers, software and user's manual, Artech House 2002, ISBN: 1-58053-488-0

9. Y. Okumura., E. Ohmori, T. Kawano and K. Fukuda "Field strength and its variability in the VHF and UHF land mobile service" Review Electronic Communication Laboratories, 16(9/10), 1968 , pp. 825-873.

10. T. K. Sarkar, S. Burintramart, N. Yilmazer, Y. Zhang, A. De and M. Salazar-Palma, "A look at the concept of channel capacity from a Maxwellian viewpoint", IEEE Antennas and Propagation Magazine, vol.50, Issue 3, June 2008, pp. 21-50

11. M V S N Prasad and K Ratnamala, "Experimental investigation of mobile radio propagation at $1.8 \mathrm{GHz}$ over macrocellular dense urban regions of Delhi", Annales of telecommunications (France), DOI 10.1007/s12243-010-0161-7,2010

12. ITU-R, P.1411-4, Propagatio data and prediction methods for the planning of short-range outdoor radiocommunication systems and radio local area networks in the frequency range 300 $\mathrm{MHz}$ to $100 \mathrm{GHz}$, International telecommunication union, Geneva 
13. Dmitry Chizhik and J. Ling, "Propagation over clutter: Physical stochastic model", IEEE Trans. on Antennas and Propagation, vol.56, No.4, April 2008, pp 1071-1077

14. Erceg V, Hari K V S, Smith M S, Baum D S, Sheikh K P, Tappenden C, Costa J M, Bushue C, Sarajedini A, Schwartz R, Branlund D, Kaitz T and Trinkwon D, "Channel models for fixed wireless applications", Contribution IEEE P 802.16 3C-01/29r4, IEEE 802.16

15. Saunders S M “Antennas and propagation for wireless communication systems", John Wiley\& sons, Ltd, 2001

16. N.Yarconi, N. Blaunstein and D.Katz, "Link budget and radio coverage design for various multipath urban communication links", Radio Science, Vol.42,RS2009, doi: 10.1029/2005RS003345, 2007, pp1-15.

17.Erceg V, Tjandra S Y, Parkoff S R, Ajay Gupta, Boris kulic, Julius A A and Renee Bianchi,

"An empirically based path loss model for wireless channels in suburban environments", IEEE J Selected areas in Communs, July 1999, Vol.17, No.7, pp 1205-1211

18. Michaelides C P and Nix A R "Accurate high speed urban field strength predictions using a new hybrid statistical deterministic modeling technique", $54^{\text {th }}$ Vehicular technology conf, Atlanta, NJ, USA, Vol.2 pp 1088-1092, 7-11 oct 2001

19. Milanovic J., Rimac-Drlje and Bejuk K.,"Comparison of propagation models accuracy for wimax on $3.5 \mathrm{GHz}$ ", ICECS 2007, $14^{\text {th }}$ IEEE international conf., Electronics circuits and systems, 11-14, Dec 2007, pp 111-114

20. K.T.Herring, J.W.Holloway, D. H. Staelin and D.W. Bliss, "Path loss characteristics of urban wireless channels", IEEE Transactions on Antennas and Propagation, Vol.58, No.1, Jan 2010, pp 171-177

21. Barbiroli M, Carciofi C, Falciasecca G, Frullone M, Grazioso P and Varini A "A new statistical approach for urban environment propagation modeling", IEEE Trans Veh. Technology, Sept 2002, Vol.51, pp 1234-1241

Acknowledgements: Authors are grateful to Mr Aswani Khilnani of Idea cellular networks and Mr Rajendra Singh of TRAI for their help in conducting the measurements.

Figure Captions:

Fig 1. Comparison of various models with observed results for MPH base station

Fig 2. Comparison of various models with observed results for MAM base station

Fig 3. Comparison of various models with observed results for RHN base station

Fig 4. Comparison of various models with observed results for ACL base station

Fig 5. Comparison of various models with observed results for IC base station

Fig 6. Comparison of various models with observed results for OM-1 base station

Fig 7. Comparison of various models with observed results for OM-2 base station

Fig 8. Comparison of various models with observed results for TRN base station

Fig 9. Comparison of various models with observed results for IPE base station

Fig 10. Comparison of various models with observed results for BJV base station

Fig 11. Comparison of various models with observed results for VDR base station

Fig 12. Variation of path loss exponent with distance for OM-1 base station

Fig 13. Variation of path loss exponent with distance for MAM base station

Fig 14. Variation of path loss exponent with distance for BJV base station 